An integrated fuzzy fault tree model with Bayesian network-based maintenance optimization of complex equipment in automotive manufacturing

\author{
Hamzeh Soltanali ${ }^{1}$, Mehdi Khojastehpour*2, ${ }^{*}$ osé Torres Farinha ${ }^{3}$
}

1-Postdoc researcher, Department of Biosystems Engineering, Ferdowsi University of Mashhad, Mashhad, Iran, Email: ha.soltanali@mail.um.ac.ir

2- Professor, Department of Biosystems Engineering, Ferdowsi University of Mashhad, Mashhad, Iran, *Corresponding author email: mkhpour@um.ac.ir

3- Professor, Centre for Mechanical Engineering, Materials and Processes (CEMMPRE), ISEC Coimbra Institute of Engineering, Coimbra, Portugal, Email: torres.farinha@dem.uc.pt 


\title{
An integrated fuzzy fault tree model with Bayesian network-based maintenance optimization of complex equipment in automotive manufacturing
}

\begin{abstract}
Knowledge-based approaches are useful alternatives to predict the Failure Probability (FP) coping with the insufficient data, process integrity and complexity issue in manufacturing systems. This study proposes a Fault Tree Analysis (FTA) approach as proactive knowledgebased technique to estimate the FP based maintenance planning with subjective information from domain experts. However, the classical-FTA still suffers from the uncertainty and static structure limitations which poses a substantial dilemma in predicting FP. To deal with the uncertainty issues, a Fuzzy-FTA (FFTA) model was developed by statistical analysing the effective attributes such as experts' trait impacts, scales variation and, assorted membership and defuzzification functions. Besides, a Bayesian Network (BN) theory was conducted to overcome the static limitation of classical-FTA. The results of FFTA model revealed that the changes in decision attributes were not statistically significant on FP variation while BN model considering conditional rules to reflect the dynamic relationship between events had more impact on predicting FP. After all, the integrated FFTA-BN model was used in optimization model to find the optimal maintenance intervals according to estimated FP and total expected cost. As a practical example, the proposed model was implemented in a semi-automatic filling system in an automotive production line. The outcomes could be useful for upgrading the availability and safety of complex equipment in manufacturing systems.
\end{abstract}

Keywords: Automotive industry, Bayesian network, Fault tree analysis, Fuzzy set theory, Maintenance optimization, Uncertainty. 


\begin{tabular}{clcl}
\multicolumn{2}{l}{ Abbreviation list } & & \\
\hline Abbreviation & Description & Abbreviation & Description \\
\hline FTA & Fault Tree Analysis & TE & Top Event \\
BNs & Bayesian Networks & BEs & Basic Events \\
IFS & Intuitionistic Fuzzy Set & IEs & Intermediate Events \\
FFTA & Fuzzy Fault Tree Analysis & ETA & Event Tree Analysis \\
FPS & Fuzzy Possibility Score & HACCP & Hazard Analysis Critical \\
CPTs & Conditional Probability Tables & HAZOP & Hazard and Operability Study \\
FMEA & Failure Mode and Effect Analysis & MCS & Minimal Cut Set \\
ABS & Anti-lock Braking System & PLC & Programmable Logic \\
PCS & Pressure Control Set & & Controller \\
MF & Membership Function & END & Event Not Developed \\
DAG & Directed Acyclic Graph & LE & Linguistic Expression \\
FP & Failure Probability & CPTs & Conditional Probability Tables \\
\hline
\end{tabular}

\section{Introduction}

With the advent of new technologies and increasing systems' complexity in modern manufacturing industries, the reliable and effective maintenance programs are required to ensure the high level of productivity and availability at the lowest cost and less number of unexpected shutdowns (Ayvaz and Alpay, 2021; Holgado et al., 2020). In this context, the risk and reliability-based approaches have received the most attention from researchers to support maintenance activity decisions within process-oriented systems (Soltanali et al., 2021: Chemweno et al., 2018; Alizadeh and Sriramula, 2017; Kiran et al., 2016). Moreover, such approaches have been widely used in diagnosing critical hotspots, troubleshooting and continues monitoring of systems with regard to data-driven and knowledge-based methods (Garmabaki et al., 2020; Alzghoul et al., 2014).

Knowledge-based approaches are recognized as very useful techniques with that of data drivenbased methods for evaluating risk and reliability, fault detection, and maintenance decision making face the imprecise and insufficient data related to equipment failures, environmental 
factors, and human activities (Leimeister and Kolios, 2018; Yazdi and Soltanali, 2018; Kumar, 2014). There are many types of knowledge-based techniques that chiefly refer to risk and reliability analysis such as Failure Mode and Effect Analysis (FMEA), Hazard Analysis Critical Control Points (HACCP), Hazard and Operability Study (HAZOP), Event Tree Analysis (ETA), Fault Tree Analysis (FTA), etc. (Jin et al., 2021; Soltanali et al., 2020a; Leimeister and Kolios, 2018; Zhang et al., 2018; Yildiz et al., 2014; Venkatasubramanian et al., 2003).

In such direction, the FTA technique is recognized as a powerful diagnosis tool which has been one of the most important knowledge-based methods since twentieth century. It is known as a deductive procedure in which the combinations of both system faults and human errors can be determined (Kumar and Kaushik, 2020; Yazdi et al., 2019). In general, the FTA analyses are classified into qualitative and quantitative levels. In qualitative analysis, the tree networks are transferred into Minimal Cut Sets (MCSs) consisting of the smallest combinations of Basic Events (BEs) to cause the Top Event (TE). In quantitative analysis, the probability of the occurrence for the TE and other indicators with like importance measures are mathematically computed (Bobbio et al., 2001; Summers, 2000). After designing the FTA structure, the outcomes could give some indications about system reliability and enable the analysist to determine which unit of a system are in urgent risk, so that the corrective actions may adapt for such critical units. In fact, the analysis procedure reflects how failures of units, human error or environmental factors could result in system failure (Kabir et al., 2019; Berrouane and Lounis, 2013). Furthermore, FTA are regularly being performed for improving product quality and availability through prevention of unexpected failures using the convenient maintenance activities in various industrial systems (Liu et al., 2017; Rusin and Wojaczek, 2012; Rice, 2007; Lapp, 2005).

In particular, automotive manufacturer industries are required to improve their productivity, process safety and availability at the less number of showdowns. Accordingly, a reliable 
maintenance program could provide a beneficial service to fulfil such objectives. Besides, they still suffer from some aleatory uncertainties derived by integrity and complexity of new equipment, dependency issue between failures, as well as epistemic uncertainties due to the lack of precise and sufficient data to acquire a well-structured maintenance program (Soltanali et al., 2020b; Soltanali et al., 2019).

To handle such deals, the present study contributes by proposing a new framework of maintenance optimization using an improved FTA technique. Moreover, this paper focuses on computational intelligence and decision tree networks techniques intervening main attributes to deal with the epistemic uncertainty and static limitations of classical-FTA. As a consequence, the proposed framework of maintenance optimization could help engineers to make better decisions on how to improve the availability and safety of complex equipment within the automotive production lines.

The remaining of this paper is structured as follows: Section "Literature review" deals with a summary of literature related to FTA concept and its diverse applications and drawbacks. Section "Research methodology" consists of a new framework of maintenance optimization using an improved FTA intervening the computational intelligence and graphical techniques. Section "Results and discussion" entails the main results of proposed framework by mean of an empirical case study and, finally, section "Conclusion" summarizes the concluding remarks and future directions.

\section{Literature review}

FTA technique has been extensively used within numerous industrial systems aimed at diverse applications; for instance, assessment of system safety in nuclear reactor and gas distribution systems (Purba et al., 2011; Berrouane and Lounis, Z, 2016), analysis of risk and reliability in automotive, chemical and petrochemical sectors (Baig et al., 2013; Lambert, 2004; Kim et al., 2005), diagnosis and prognosis of faults/failures in electric power, electronic components, 
pipelines, aerospace (Volkanovski et al., 2009; Yuhua and Datao, 2005), maintenance tasks implication in medical device, mining, chemical processes, mechanical systems, etc. (Rusin and Wojaczek, 2012; Rice, 2007; Gupta et al., 2006; Khan and Haddara, 2004), and so on.

Despite many advantages and successful feedback of the classical-FTA technique, it has been criticized for a number of shortcomings and limitations such as, simplifying the model owing to the system' complexity and lack of knowledge about system behaviour, assuming the independence of events, possibility of human error while specifying the logical structure of fault trees and presence of the redundant or common cause failures (Yazdi et al., 2019; Kumar and Kaushik, 2020). Such fluctuations not only may affect the accuracy of expected analysis results, but also implementing proper corrective decisions and solutions. Therefore, to improve the credibility of the results of FTA, the uncertainties are required to be handled. The computational intelligence and decision tree network techniques/theories have been commonly addressed to take the uncertainties into account and supplement the classical-FTA calculations. In that direction, fuzzy set theory has been widely referred to handle uncertainty issues of FTA. Recently, Aghaei et al., (2021) developed a Fuzzy-FTA (FFTA) model for the risk assessment of functional safety in shopping centre construction projects to identify the origin of the risks and to offer suitable management responses to such risks. In another research, Yazdi et al., (2020) established a FFTA using expert opinion to compute the probability of an event. In order to reduce the probability of the TEs in terms of three parameters (safety consequences, cost, and benefit), an importance measurement technique was employed. Akhtar and Kirmani, (2020) applied a FFTA framework for reliability evaluation of a wind energy system. The outcomes showed that the fuzzy-based technique can combine the probabilities imprecision and inaccuracy in reliability engineering. Zhou and Ren, (2020) conducted a novel FFTA method in the assumption of the values of probability of BEs expressed with triangular intuitionistic fuzzy numbers. An example of weapon system is employed to reflect the 
effectiveness of proposed FFTA method. In another study, a novel approach to evaluate system Failure Probability (FP) was developed using FFTA with qualitative failure data. In this study, the linguistic terms are quantified by triangular intuitionistic fuzzy numbers (Kuzu et al., 2019). Due to the lack of historical data for calculating the failure rate of oil and natural gas pipelines, a FFTA framework with expert elicitation was carried out. The results could help safety professionals while making decisions related to the risk management of oil and gas pipelines (Badida et al., 2019). Moreover, a remarkable number of studies have been made for fault diagnosis, probability of failures, and risk and reliability analysis in process industries using FFTA model (Yazdi, and Zarei, 2018; Yazdi and Darvishmotevali, 2018; Yazdi et al., 2017; Yazdi, 2017). Prior to such studies, Rajakarunakaran et al., (2015) proposed a FFTA model to quantify the fault tree of LPG refuelling facility in the absence or existence of data. The results revealed that the approach is very beneficial for the probabilistic reliability estimation. Meanwhile, Kumar and Yadav, (2012) applied the weakest t-norm based intuitionistic FFTA to evaluate system reliability by finding the most critical units that affects the system reliability. In the other hand, the decision tree networks in particular Bayesian Networks (BNs) have been very prevalent to overcome the static structure limitation of FTA. In fact, BNs as the wellknown graphical model tend to create a causal relationship between key factors (causes) and one or more final outcomes in a system (Zheng et al., 2019; Yazdi and Soltanali, 2019; Rausand, 2013; Jong and Leu, 2013). BN analysis may be qualitative, quantitative, or both, depending on the scope of the analysis and also, they are very popular in statistics, machine learning, artificial intelligence as well as risk and reliability analyses (Bouejla et al., 2014; Hänninen et al., 2014; Huang et al., 2006; Khakzad et al., 2013). In recent years, the integrated FTTA-BN model has been very effective to handle the major subjective uncertainties of classical template of FTA aimed at usability for the risk and reliability assessment, fault 
analysis and failure diagnosis and prognosis (Aydin et al., 2021; Kabir et al., 2019; Yazdi and Kabir, 2017; Smith et al., 2017; Chiremsel and Chiremsel, 2016).

Based on literature, in order to build up such models, often the Triangular (Trimf) or Trapezoidal (Trapmf) as the core Membership Function (MF), the centre of gravity (Centroid) technique as main defuzzification algorithm and three or five-linguistic scale as main fuzzy numbers are assumed as basis of FTA analyses. However, to the best of authors knowledge, the accuracy and capability of other type of functions and algorithms have not yet been investigated by researchers. As main motivation, this study contributes to make a comprehensive survey on the effect of various membership functions, linguistic scale of fuzzy numbers and defuzzification algorithms to ensure a well-established FTTA-BN model. Besides, the effect of experts' traits was addressed to obtain a more reliable estimation of reliability function so that it could be included into the maintenance optimization model in the next step. Additionally, the most FTTA-BN models have focused mainly on the risk and reliability analysis as well as maintenance tasks implication, while less attention using the outcomes in the scheduled-based maintenance tasks. Hence, another objective of this study is to obtain an optimal maintenance plan by solving an optimization problem under the developed FTTA-BN model. As a consequence, due to the process integrity and complexity issue of new equipment, dependency between units' failures, as well as the importance of the safety guarantee and process availability in manufacturing systems, the proposed framework was implemented in a complex semi-automatic filling system in the automotive production line aimed at helping the engineers to be able to manage the operation and maintenance tasks, effectively. 


\section{Research methodology}

The proposed framework of maintenance optimization based on FFTA-BN model is shown in Fig.1. FTA and $\mathrm{BN}$ models construction, expert judgment process, and maintenance optimization are three key factors in the proposed framework. First, the TE is identified as the main problem. After that, the computations need to be classified into qualitative and quantitative levels. For qualitative analysis, the FTA structure is constructed to determine the root cause of the TE affected by Intermediate Events (IEs) and BEs, as well as to clarify the relationship of events statically with the aid of logic gates at the level of system's components. Followed by, in quantitative analysis, the experts' knowledge and fuzzy set theory are utilized to calculate the probability of failure and system reliability in terms of each Minimal Cut Set (MCS) in FFTA model. The results of FFTA are employed as input factors in the BN structure, so that the reliability function is predicted under dynamic relationship between events. Finally, the results of combined FFTA-BN model is applied into optimization model to predict the optimal maintenance intervals. The details of each step are provided as follows:

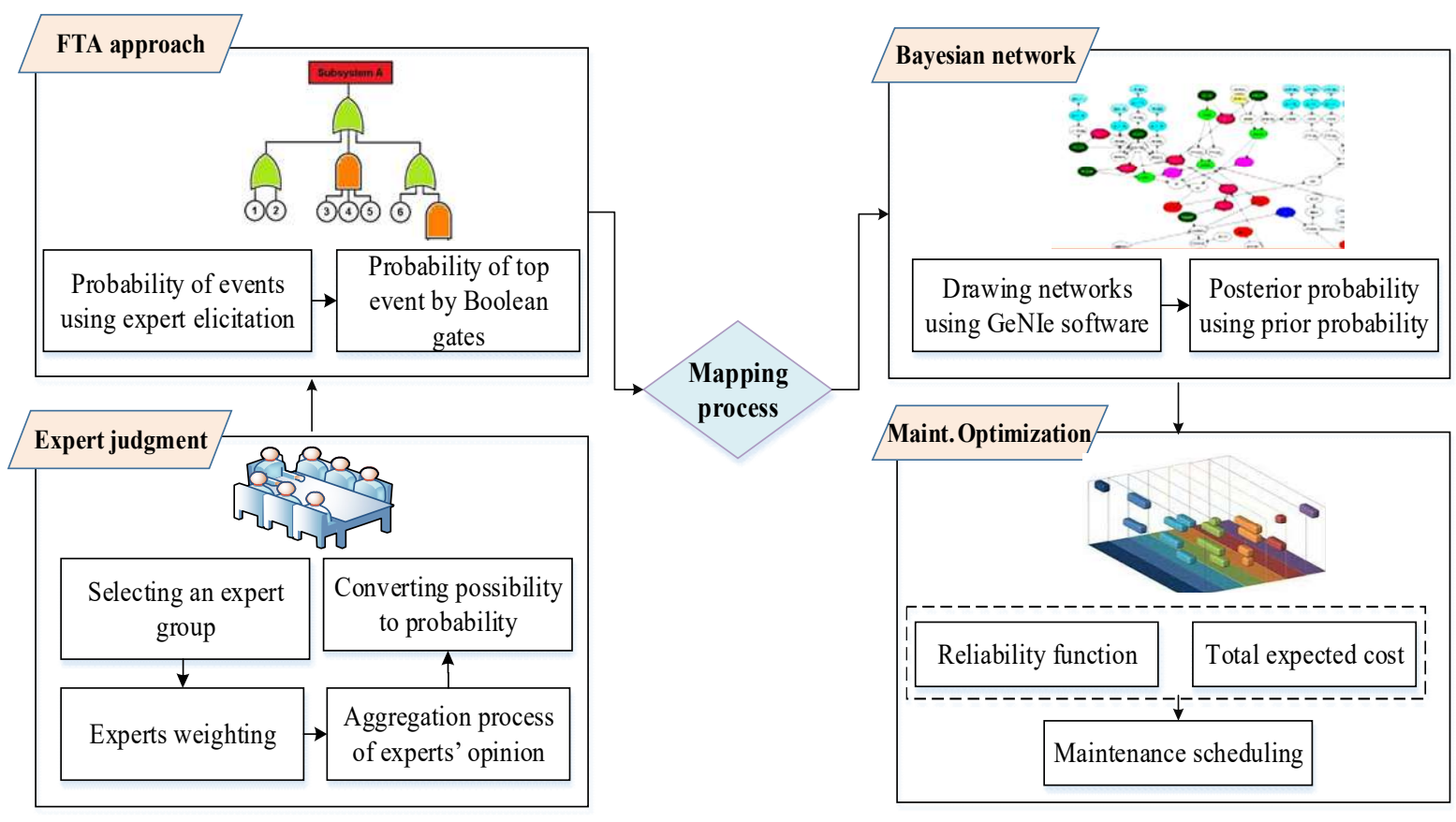

Fig. 1. The proposed framework of FFTA-BN structure-based maintenance optimization 


\subsection{Theory of FTA approach}

FTA belongs to the deductive methods used for identifying the occurrences in equipment or systems that could result in system failure. It provides interrelations between occurrences through graphical representation that can result in system failure. (Farinha, 2018). FTA is started with a specified potential critical event in the system, named as $T E$. In qualitative analysis, $T E$ can be initiated from the $B E s$ or in combination with Intermediate Event (IES) towards $T E$ which are linked through the logical $A N D / O R$ gates. All BEs, from the $T E$ to the down are supposed to be binary events that either occur or do not occur, which means that FTA is also a deterministic method. Table 1 shows the graphical symbols commonly used in FTA structure. For instance, from the logic gates, $O R$ gate, indicates that there is an occurrence at the output, since there is at least one entry. Besides, $A N D$ gate implies that there is an occurrence at the output only when there are simultaneous occurrences in all entries (Farinha, 2018; Yazdi and Soltanali, 2018).

Table 1. Main symbols and construction of a fault tree adapted from (Farinha, 2018)

Item
Logic gates:
-OR gate $(O R)$
-Basic Event $(B E)$
-Events:
-Intermediate Event $(I E)$

In quantitative analysis level, the $F P$ of $T E$ or $P(T)$ by estimating the $F P$ of $B E s$ or $P\left(X_{i}\right)$ under AND/OR gates, can be computed as follows (Cheliyan and Bhattacharyya, 2018). 


$$
P(T)=\left\{\begin{array}{l}
\prod_{i=1}^{N} P\left(X_{i}\right) \text { for AND gate } \\
1-\prod_{i=1}^{N}\left(1-P\left(X_{i}\right)\right) \text { for Or gate }
\end{array}\right.
$$

where $N$ is the number of $B E \mathrm{~s} . P\left(X_{i}\right)$ is the $F P$ of the event $X i . P(T)$ is the probability of failure of $T E$. The FP of the $T E$ is evaluated by obtaining its Minimal Cut Sets (MCS). Once all the MCSs, denoted $C_{i}\left(i=1,2, \ldots, N_{c}\right)$ where $N_{c}$ is the number of $M C S$, are determined, the FP of the $T E$, denoted $P(T)$, is given by

$$
P(T)=1-\prod_{i=1}^{N_{c}}\left(1-P\left(C_{i}\right)\right)
$$

where $P\left(C_{i}\right)$ is the FP of $C_{i}$. As long as the failure probabilities of the $B E$ s are small, (i.e., $P\left(X_{i}\right)$ $\leq 1)$, the above estimate of $P(T)$ can be approximated well by

$$
P(T) \approx \sum_{i=1}^{N_{c}} P\left(C_{i}\right)
$$

A typical $M C S$ is a collection of the $B E$ s and may be denoted as

$$
C_{i}=\overline{X_{1}}, \overline{X_{2}}, \ldots, \overline{X_{N_{j}-1}}, \overline{X_{N_{j}}} \text { where } \overline{X_{i}} \in\left(X_{1}, X_{2}, \ldots, X_{N}\right)
$$

where $N_{j}$ is the number of $B E \mathrm{~s}$ in $C_{j}$, also called the order of the $M C S$. On the other hand, there are several ways to compute the probability of all BEs such as expert judgment, extrapolation, and statistical-based methods. In this study, the experts' knowledge is utilized to calculate the probability of failures. Due to the various opinion, information, experience, and intellectual attributes of experts, it may lead to a number of uncertainties in the probability of failure values. Therefore, a combination of expert opinions should be used for this purpose. On the other hand, the FTA team in terms of age, expertise, skill, experience, knowledge level, etc. are almost heterogeneous that needs to be handled. The main experts' attributes and their weights are described in Table 2 (Yazdi and Soltanali, 2018). 
Table 2. Weight rating according to experts' attributes

\begin{tabular}{cccccc}
\hline Item & Categorize & weight & Item & Categorize & weight \\
\hline \multirow{4}{*}{ Education } & PhD & 5 & & Higher-ranking & 5 \\
& Master & 4 & Profession & Low-ranking academic & 4 \\
& Bachelor & 3 & position & Engineer & 3 \\
& Associate & 2 & Technician & 2 \\
& Diploma & 1 & Worker & 1 \\
& More than & 4 & & More than 20 years & 5 \\
Age & 40 & 3 & & $16-20$ & 4 \\
& $36-39$ & 3 & Job Tenure & $10-15$ & 3 \\
& $30-35$ & 2 & $6-9$ & 2 \\
& Less than 30 & 1 & & $\leq 5$ & 1 \\
\hline
\end{tabular}

The weighting score of an expert is the summation of these weights for attributes. The weighting factor for each expert is then computed by (Cheliyan and Bhattacharyya, 2018).

$$
\text { Weighting factor of the expert }=\frac{\text { Weighting score of the expert }}{\text { Sum of weighting scores of all experts }}
$$

Table 3 shows the experts' weights and their characteristic to accomplish the process judgments in the FTA approach in the present study.

Table 3. Expert weighting of group decision-making for the present study

\begin{tabular}{cccccc}
\hline Expert & Education & Age & Profession position & Job Tenure & Weighting score (w) \\
\hline Expert 1: & Bachelor (3) & $36(2)$ & Process Engineer (3) & $15(3)$ & 0.234 \\
Expert 2: & Master (4) & $38(3)$ & Mechanical Engineer (3) & $13(3)$ & 0.276 \\
Expert 3: & Bachelor (3) & $46(2)$ & Electrical Engineer (3) & $16(4)$ & 0.255 \\
Expert 4: & Bachelor (3) & $42(2)$ & Safety Engineer (3) & $14(3)$ & 0.234 \\
Total & 13 & 9 & 12 & 13 & $47 / 47=1$ \\
\hline
\end{tabular}

Besides, linguistic expressions were used to fulfil the experts' opinions about probability of the BEs. Moreover, the fuzzy numbers are adapted to handle such linguistic expressions. In this study, three modes of 3-scale, 5-scale, and 10-scale of fuzzy linguistic expressions were evaluated along with four types of Membership Functions $(M F s)$ including: Triangular-shaped (Trimf), Trapezoidal-shaped (Trapmf), П-shaped (Pimf) and Gaussian (Gaussmf) (Table 4, 5 and 6) (Soltanali et al., 2020a; Hsu and Chen, 1992; Yazd et al., 2017). 
Table 4. 3-scale fuzzy with 4 membership function

\begin{tabular}{cccc}
\hline Rank & Linguistic expression & MF function & Fuzzy number \\
\hline \multirow{3}{*}{$1,2,3$} & Trapmf & $(0.0,0.0,0.02,0.04)$ \\
& Low $(\mathrm{L})$ & Trimf & $(0.0,0.02,0.04)$ \\
& Gaussmf & $(0,0,0.07,0.22)$ \\
$4,5,6,7$ & Pimf & $(0.0,0.0,0.22,0.38)$ \\
& Medium $(\mathrm{M})$ & Trapmf & $(0.23,0.47,0.53,0.77)$ \\
& & Trimf & $(0.2,0.5,0.8)$ \\
& & Gaussmf & $(0.10,0.47,0.50,0.53)$ \\
& & Pimf & $(0.23,0.47,0.53,0.77)$ \\
\hline \multirow{2}{*}{$8,9,10$} & High $(\mathrm{H})$ & Trapmf & $(0.6,0.8,1.0,1.0)$ \\
& & Trimf & $(0.6,0.8,1.0)$ \\
& & Gaussmf & $(0.7,0.8,0.9,1.0)$ \\
& & Pimf & $(0.62,0.78,1.0,1.0)$ \\
\hline
\end{tabular}

Table 5. 5-scale fuzzy with 4 membership function

\begin{tabular}{|c|c|c|c|}
\hline Rank & Linguistic expression & MF function & Fuzzy number \\
\hline 1 & Very low (VL) & $\begin{array}{l}\text { Trapmf } \\
\text { Trimf } \\
\text { Gaussmf } \\
\text { Pimf }\end{array}$ & $\begin{array}{c}(0.0,0.0,0.1,0.2) \\
(0.0,0.1,0.2) \\
(0.0,0.0,0.03,0.11) \\
(0.00,0.00,0.11,0.19)\end{array}$ \\
\hline 2,3 & Low (L) & $\begin{array}{l}\text { Trapmf } \\
\text { Trimf } \\
\text { Gaussmf } \\
\text { Pimf }\end{array}$ & $\begin{array}{c}(0.1,0.2,0.3,0.4) \\
(0.05,0.25,0.45) \\
(0.03,0.19,0.03,0.31) \\
(0.11,0.19,0.31,0.39)\end{array}$ \\
\hline $4,5,6$ & Medium (M) & $\begin{array}{l}\text { Trapmf } \\
\text { Trimf } \\
\text { Gaussmf } \\
\text { Pimf }\end{array}$ & $\begin{array}{c}(0.3,0.4,0.6,0.7) \\
(0.20,0.50,0.80) \\
(0.03,0.39,0.03,0.61) \\
(0.31,0.39,0.61,0.69)\end{array}$ \\
\hline 7,8 & $\operatorname{High}(\mathrm{H})$ & $\begin{array}{l}\text { Trapmf } \\
\text { Trimf } \\
\text { Gaussmf } \\
\text { Pimf }\end{array}$ & $\begin{array}{c}(0.6,0.7,0.8,0.9) \\
(0.55,0.75,0.95) \\
(0.03,0.69,0.03,0.81) \\
(0.61,0.69,0.81,0.89)\end{array}$ \\
\hline 9,10 & Very high (VH) & $\begin{array}{l}\text { Trapmf } \\
\text { Trimf } \\
\text { Gaussmf } \\
\text { Pimf }\end{array}$ & $\begin{array}{c}(0.8,0.9,1.0,1.0) \\
(0.8,0.9,1.0) \\
(0.03,0.89,1.00,1.00) \\
(0.81,0.89,1.00,1.00)\end{array}$ \\
\hline
\end{tabular}

Table 6. 10-scale fuzzy with 4 membership function

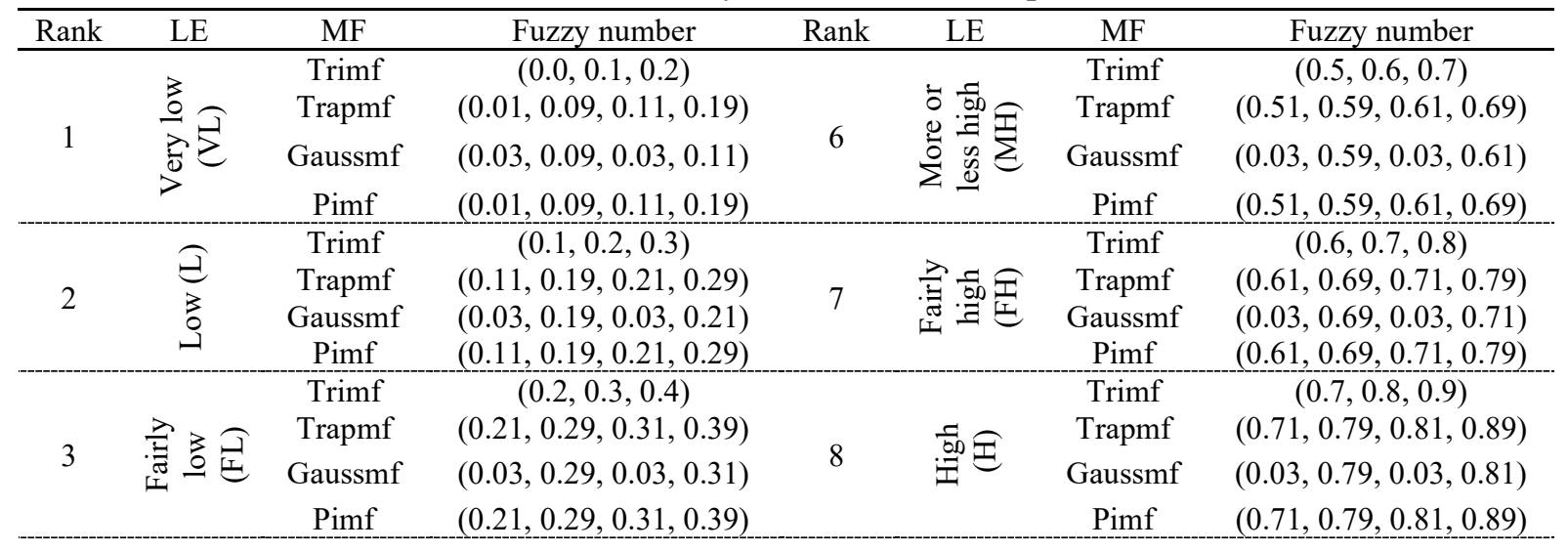




\begin{tabular}{|c|c|c|c|c|c|c|c|}
\hline 4 & 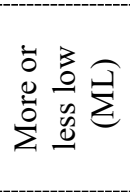 & $\begin{array}{l}\text { Trimf } \\
\text { Trapmf } \\
\text { Gaussmf } \\
\text { Pimf }\end{array}$ & $\begin{array}{c}(0.3,0.4,0.5) \\
(0.31,0.39,0.41,0.49) \\
(0.03,0.39,0.03,0.41) \\
(0.31,0.39,0.41,0.49)\end{array}$ & 9 & 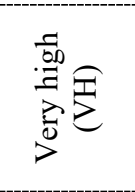 & $\begin{array}{l}\text { Trimf } \\
\text { Trapmf } \\
\text { Gaussmf } \\
\text { Pimf }\end{array}$ & $\begin{array}{c}(0.8,0.9,1.0) \\
(0.81,0.89,0.91,0.99) \\
(0.03,0.89,0.03,0.91) \\
(0.81,0.89,0.91,0.99)\end{array}$ \\
\hline 5 & $\stackrel{\Xi}{\Xi} \underset{\Xi}{\Xi}$ & $\begin{array}{c}\text { Trimf } \\
\text { Trapmf } \\
\text { Gaussmf } \\
\text { Pimf }\end{array}$ & $\begin{array}{c}(0.4,0.5,0.6) \\
(0.41,0.49,0.51,0.59) \\
(0.03,0.49,0.03,0.51) \\
(0.41,0.49,0.51,0.59)\end{array}$ & 10 & 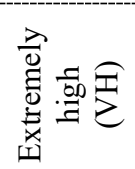 & $\begin{array}{l}\text { Trimf } \\
\text { Trapmf } \\
\text { Gaussmf } \\
\text { Pimf }\end{array}$ & $\begin{array}{c}(0.9,1.0,1.0) \\
(0.91,0.99,1.00,1.00) \\
(0.03,0.99,1.00,1.00) \\
(0.91,0.99,1.00,1.00)\end{array}$ \\
\hline
\end{tabular}

LE: Linguistic Expression, MF: Membership Function

In this section, aggregation process of expert judgments was assigned to achieve a reliable decision, because each expert might have a variety of opinions about failure probability. This process is conducted via the five following steps (Yazd et al., 2017):

1.Calculating degree of similarity between opinion of every two experts $S\left(\tilde{A}, B^{\tilde{B}}\right)$ Eq. (6):

$$
S(\tilde{A}, \tilde{B})=1-\frac{1}{J} \sum_{i=1}^{J}\left|a_{i}-b_{i}\right|
$$

where $J$ is the parameters of the membership function; $a_{i}$ and $b_{i}$ are also the parameters of the membership function.

2.Computing the Relative Agreement $(R A)$ degree, $\left(A A\left(E_{u}\right)\right)$ of expert's opinion Eq. (7):

$$
A A\left(E_{u}\right)=\frac{1}{J-1} \sum_{v=1, u \neq v}^{J} S\left(\tilde{R}_{u}, \tilde{R}_{v}\right)
$$

3.Computing the Relative Agreement $\left(R A\left(E_{u}\right)\right)$ degree, of expert's opinion Eq. (7):

$$
R A\left(E_{u}\right)=\frac{A A\left(E_{u}\right)}{\sum_{u=1}^{J} A A\left(E_{u}\right)}
$$

4. Calculating the consensus coefficient degree of expert's opinion $\left(C C\left(E_{u}\right)\right)$ Eq. (9):

$$
C C\left(E_{u}\right)=\beta W\left(E_{u}\right)+(1-\beta) \cdot R A\left(E_{u}\right)
$$

where, $W$ is the weight of each expert, $\beta$ is relaxation factor $(0 \leq \beta \leq 1)$ wherever it can be used for sensitivity analysis to determine sensible effect of expert's traits on experts' opinion.

5. Computing the final result of expert's opinions $\left(\widetilde{\mathrm{R}}_{\mathrm{AG}}\right)$ Eq. (10):

$$
\tilde{R}_{A G}=C C\left(E_{1}\right) \otimes \tilde{R}_{2} \oplus C C\left(E_{2}\right) \otimes \tilde{R}_{2} \oplus \ldots \oplus C C\left(E_{m}\right) \otimes \tilde{R}_{M}
$$

where $\oplus$ is a fuzzy sum operation and $\otimes$ is a fuzzy scalar multiply operation. $\widetilde{R}_{A G}$ is a fuzzy set in which the defuzzification method must be used to calculate a single point value called Fuzzy Possibility Score (FPS) which represents the possibility of the BEs. For this purpose, 
five algorithms including centroid, bisector, smallest of maximum (som), middle of maximum (mom) and largest of maximum (lom) were applied. Finally, the FPS of all $B E_{s}$ needs to be converted to their $F P$ or $P\left(X_{i}\right)$ in which the values can be varied between 0 tol. The $F P$, as defined by Onisawa (1998), is given by:

$$
P(x)=\left\{\begin{array}{ll}
\frac{1}{10^{k}} & \text { for } F P S \neq 0 \\
0 & \text { for } F P S=0
\end{array} \quad k=2.301\left(\frac{1-F P S}{F P S}\right)^{\frac{1}{3}}\right.
$$

A computer programming was deployed in MATLAB-vR-2020b (MathworksInc, US) to calculate the $P\left(X_{i}\right)$ in FFTA model.

\subsection{Mapping FFTA into BN model}

In order to handle the static drawback of FFTA model, a Bayesian updating mechanism was conducted. In fact, a Bayesian network $(B N)$ is a graphical model which provides the causal relationship between causes in a system. It entails a set of random variables represented by root, intermediate and leaf nodes, bounded by oriented arcs or Directed Acyclic Graph $(D A G)$ and accompanied by their conditional dependencies. In $B N$, a node from which an edge/link is directed to another node is called "parent" while the other node to which the edge is called "child". In other words, a node describes a state or condition, an arc indicates a direct influence, and Conditional Probability Tables $(C P T s)$ implies the conditional independency relationships between parent-child nodes. The probabilities of the root events are assigned to the corresponding root nodes as prior probabilities, while for intermediate nodes as well as the leaf nodes (TEs), CPTs need to be developed (Yazdi and Soltanali, 2018). In this study, the results of $F P$ are considered as prior probability for estimating posterior probability in BN. Given the conditional dependency of variables and the chain rule, $B N$ represents the joint probability distribution of a set of variables $T=\left\{X_{1}, \ldots, X_{n}\right\}$ as follows:

$$
P(T)=\prod_{i=1}^{n}\left(P\left(X_{i} \mid P_{a}\left(X_{i}\right)\right)\right.
$$


Where $P_{a}\left(X_{i}\right)$ is the parent set of variables, $X_{i}$. Accordingly, the probability of $X_{i}$ is calculated as:

$$
P\left(X_{i}\right)=\sum x_{i \neq i} P(T)
$$

During $\mathrm{BN}$ analysis, a series of evidence $(E)$ is examined, and the posterior or updated probability distribution of $X_{i}$ can be calculated using Bayes' theorem as follows:

$$
P\left(X_{i} \mid E\right)=\frac{P\left(X_{i}, E\right)}{P(E)}=\frac{P\left(E \mid X_{i}\right) \cdot P\left(X_{i}\right)}{\sum_{V} P\left(X_{i} \mid E\right) \cdot P\left(X_{i}\right)}
$$

where, $P(X i \mid E)$ is the posterior probability under a given evidence $E, P(X i)$ is the prior probability of event $X i, P(E \mid X i)$ is the evidence likelihood of the given event $X i, P(E)$ is the pre-defined posterior probability of evidence, and $\sum_{V} P\left(X_{i} \mid E\right) \cdot P\left(X_{i}\right)$ is the joint probability distribution of $E$. The Bayesian network mapping process as well as related calculations was made in GeNIe 3.0 academic software.

\subsection{Maintenance optimization model}

In this subsection, the outcomes of developed FFTA-BN model specifically the probability of failures and reliability indexes were employed within maintenance optimization model. The optimal maintenance interval for cycle $T$ (planning horizon) has been proposed by (Rezaei, 2017). It assumes that failures occur at times $k \tau(\tau, 2 \tau, \ldots, k \tau)$, as well as the repair is made at the end of the cycle $\mathrm{T}$ (for $k=n$, at the time $n \tau$ ). $\tau$ is the time between two consecutive maintenances, it means $\tau=T / n$. The objective is to find the optimal maintenance interval time to minimize the total expected cost of the system over the cycle $T$. Hence, the total expected cost in $k^{\text {th }}$ inspection for each cycle $(\tau)$ is given by:

$$
E_{\tau}\left[C_{\text {Total }}^{T}\right]=\sum_{i=1}^{n} \sum_{k=1}^{T / \tau} E_{\tau}\left[C_{i}^{(k-1) \tau, k \tau}\right]
$$




$$
\begin{aligned}
& \left(\begin{array}{l}
\sum_{i=1}^{n} \sum_{k=1}^{T / \tau}\left(\tau_{i}^{I} W^{I}+\tau_{i}^{I} P\right)+\sum_{i=1}^{n} \sum_{k=1}^{T / \tau}\left(\operatorname{Re}_{i}+\tau_{i}^{R} W^{R}+\tau_{i}^{R} P\right)(1-R(\mathrm{k} \tau))+ \\
\sum_{i=1}^{n} \sum_{k=1}^{T / \tau}\left(\tau_{i}^{P F} P+L\right)(1-R(\mathrm{k} \tau))
\end{array}\right) \\
& \forall \tau=T, T / 2, T / 3, \ldots, \mathrm{T} / \mathrm{T}
\end{aligned}
$$

where, $E_{\tau}\left[C_{\text {Total }}^{T}\right]$ is total expected cost, $W$ is inspection/preventive cost, $R e$ is repair/perfect replacement cost, $P$ is production loss cost and $L$ is downtime cost. In accordance with the work of Rezaei (2017), the optimal maintenance interval can be estimated as follows:

$$
\eta C=\frac{\sum_{i=1}^{n} \sum_{k=1}^{T / \tau} E_{\tau}\left[C_{i}^{(k-1) \tau, k \tau}\right]}{k \cdot \int_{0}^{\tau} R(k \tau) d t}
$$

where, $\eta C(\mathrm{k} \tau)$ is the optimal maintenance interval at $k \tau(\tau, 2 \tau, \ldots, \mathrm{k} \tau)$, and $R(k \tau)$ is the computed reliability based on proposed FTTA-BN model.

\section{Results and discussion}

\subsection{The empirical case study}

In order to implement the proposed FTTA-BN model-based maintenance optimization, a semiautomatic filling equipment as the most critical and complex system within an automotive production line was considered. The reliability and safety guarantee of such system from operational and non-operational aspects are important. In fact, the low reliability of system results in an increase in equipment breakdowns as well as assembly line showdowns. Besides, because of the importance of safety guarantee for operators and complexity issues, an effective scheduled-maintenance plan could be useful to prevent the unexpected failures. The system is in charge of filling, levelling and leakage tests in paths and pipes. Fig. 2 (a,b) shows the main blocks and a general illustration of system under filling operations. It consists of seven critical blocks such as initialization and ready blocks, pressure, vacuum and filling blocks, and 
lubrication and process end blocks which are shown in Fig. 2 (a). The main feature of these blocks is their series configuration with three sub-categories, therefore, any failure of a component in each block leads to system downtime. As seen in Fig. 2 (a), in the first subcategory, from the initialization block, if the filling system tank is under pressure, the process will equalize/release this pressure. Subsequently, the system is ready to perform filling process (Ready block). In the second sub-category, there are two pumps (including vacuum and filling pumps) as well as a Pressure Control Set (PCS) to measure pressure/vacuum level. The pressure block is used to inject air into the system and, to examine the pressure to ensure that the filing system is free of any leakage. Then, the vacuum block performs the evacuation of system and looks for any vacuum leaks for a proper vacuum level. After setting the vacuum and pressure, the filling block is used to perform the fillings with different fluid liquids and to control the level of fluids. Finally, in the third sub-category, in order to ongoing operation of the rotary equipment especially pumps, the oil is needed for lubrication during the filling process provided through a lubrication tank (Lubrication block) and eventually, in the process end block, the operator can unclamp and remove the filling head from the vehicle.

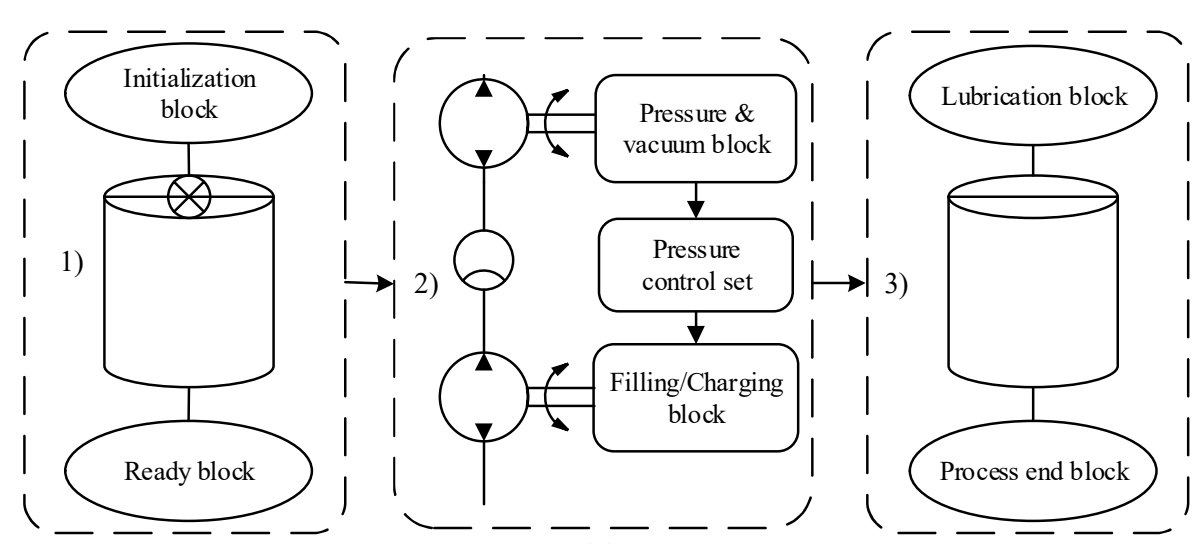

(a) 

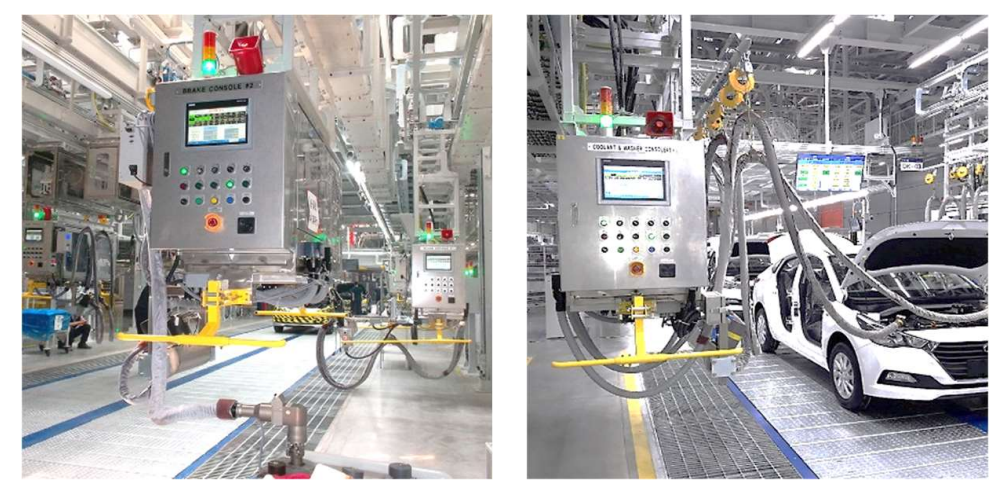

(b)

Fig. 2. A fluid filling process in the automotive industry a) block diagram b) operational view

\subsection{The FFTA-BN model results}

Fig. 3 represents a FTA structure for the failures in a fluid filling system as TE. The operational units of system include the hydraulic-pneumatic circuit, the electronic circuit, and the filling headset. The filling pump is used for fluid injection, the pressure set controls the required pressure, and the pipes and fittings are designed to transfer air and various fluids. The Electronic circuit includes a Programmable Logic Controller (PLC) unit which comprises several sensors, such as the Anti-lock Braking System (ABS) and the starters. The filling headset is mounted on the vehicles. The critical components of this set include mini-valves, pipes, couplings, and seals. The pumps, especially the vacuum pump, operate more often and they are active in all of filling process. Therefore, they are subjected to a higher occurrence of failures. The major failure modes for pumps are filtering failure, corrosive bearing, and seals failures. The main failure modes for filling headset are couplings, mini-valves, and seals. The failure modes for electronic circuit are sensors, ABS, and starter. 


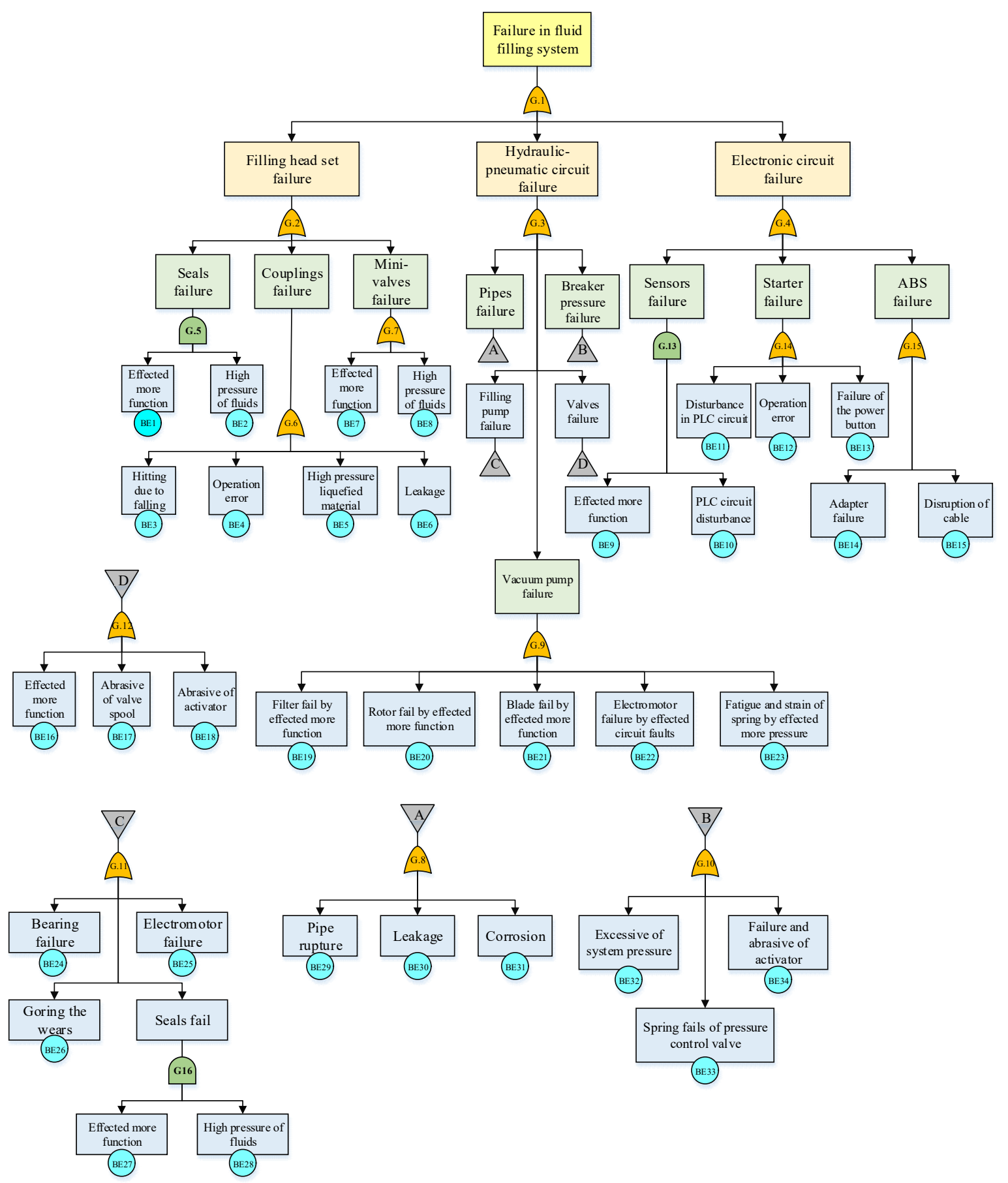

Fig. 3. The FTA structure for the failures in a fluid filling system

Table 7 illustrates 33 BEs for fluid filling system which are linked directly and/or indirectly to the specified TE. In order to calculate the FP of BEs, the questionnaire-based method was employed involving a group of experts and their opinion to express the lowest to highest value 
of FP from the range number of 1 to 10 for each BE. The experts' characteristics and their weighting results were provided in Table 3 to complete the process judgment in FTA approach.

Table 7. The details of BEs under experts' judgments

\begin{tabular}{|c|c|c|c|c|c|c|c|}
\hline Unit & Component & BE tag & BEs description & Expert 1 & Expert 2 & Expert 3 & Expert 4 \\
\hline \multirow{8}{*}{ 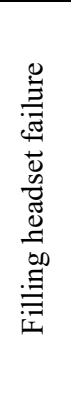 } & O-rings \& & BE.1 & Effected more function & 9 & 5 & 5 & 8 \\
\hline & $\begin{array}{l}\text { Seal's } \\
\text { failure }\end{array}$ & BE. 2 & High pressure of fluids & 4 & 5 & 5 & 3 \\
\hline & & BE. 3 & Hitting due to falling & 5 & 6 & 5 & 7 \\
\hline & Coupling's & BE.4 & Operation error & 5 & 6 & 7 & 5 \\
\hline & failure & BE.5 & High pressure liquefied material & 6 & 5 & 3 & 4 \\
\hline & & BE.6 & Leakage & 6 & 7 & 8 & 5 \\
\hline & Mini-valve's & BE.7 & Effected more function & 7 & 8 & 5 & 6 \\
\hline & failure & BE. 8 & High pressure of fluids & 7 & 5 & 3 & 5 \\
\hline \multirow{7}{*}{ 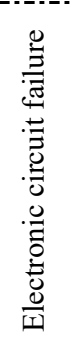 } & Sensor's & BE.9 & Effected more function & 3 & 5 & 5 & 8 \\
\hline & failure & BE. 10 & PLC circuit disturbance & 3 & 4 & 3 & 2 \\
\hline & & BE.11 & Disturbance in PLC circuit & 3 & 5 & 5 & 5 \\
\hline & failure & BE.12 & Operation error & 5 & 9 & 9 & 8 \\
\hline & & BE.13 & Failure of the power button & 3 & 9 & 9 & 8 \\
\hline & ABS's & BE.14 & Adapter failure & 8 & 9 & 8 & 9 \\
\hline & failure & BE. 15 & Disruption of cable & 8 & 9 & 8 & 8 \\
\hline \multirow{18}{*}{ 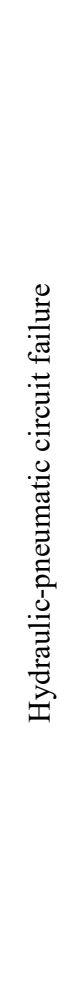 } & \multirow{3}{*}{$\begin{array}{l}\text { Valve's } \\
\text { failure }\end{array}$} & BE. 16 & Effected more function & 7 & 3 & 3 & 8 \\
\hline & & BE.17 & Abrasive of valve spool & 3 & 3 & 5 & 5 \\
\hline & & BE.18 & Abrasive of activator & 4 & 5 & 3 & 2 \\
\hline & \multirow{5}{*}{$\begin{array}{l}\text { Vacuum } \\
\text { pump's } \\
\text { failure }\end{array}$} & BE.19 & $\begin{array}{l}\text { Filters fail by effected more } \\
\text { function }\end{array}$ & 3 & 5 & 3 & 5 \\
\hline & & BE. 20 & $\begin{array}{l}\text { Rotors fail by effected more } \\
\text { function }\end{array}$ & 4 & 3 & 4 & 2 \\
\hline & & BE. 21 & $\begin{array}{l}\text { Blades fail by effected more } \\
\text { function }\end{array}$ & 3 & 3 & 7 & 5 \\
\hline & & BE.22 & $\begin{array}{l}\text { Electromotor failure by effected } \\
\text { circuit faults }\end{array}$ & 2 & 3 & 5 & 5 \\
\hline & & BE. 23 & $\begin{array}{l}\text { Fatigue and strain of spring by } \\
\text { effected more pressure }\end{array}$ & 5 & 5 & 5 & 8 \\
\hline & \multirow{5}{*}{$\begin{array}{l}\text { Filling } \\
\text { pump's } \\
\text { failure }\end{array}$} & BE.24 & Bearing failure & 4 & 3 & 2 & 5 \\
\hline & & BE. 25 & Electromotor failure & 6 & 3 & 3 & 5 \\
\hline & & BE.26 & Goring the wears & 5 & 3 & 3 & 2 \\
\hline & & BE.27 & Effected more function & 4 & 3 & 2 & 5 \\
\hline & & BE. 28 & High pressure of fluids & 4 & 3 & 2 & 6 \\
\hline & \multirow{3}{*}{$\begin{array}{l}\text { Pipe's } \\
\text { failure }\end{array}$} & BE.29 & Pipe rupture & 7 & 3 & 9 & 3 \\
\hline & & BE.30 & Leakage & 3 & 9 & 5 & 8 \\
\hline & & BE.31 & Corrosion & 3 & 3 & 7 & 8 \\
\hline & \multirow{2}{*}{$\begin{array}{l}\text { Pressure } \\
\text { control's } \\
\text { failure }\end{array}$} & BE.32 & Excessive of system pressure & 5 & 2 & 7 & 5 \\
\hline & & BE.33 & $\begin{array}{l}\text { Spring fails of pressure control } \\
\text { valve }\end{array}$ & 3 & 5 & 7 & 5 \\
\hline
\end{tabular}

The fuzzy linguistic expressions considering various fuzzy scales and diverse Membership Functions (MFs) and defuzzification algorithms were used to fulfil the experts' judgments to 
be able to predict the FP of BEs related to fluid filling system. Fig. 4 (a) to Fig. 4 (e) displays the impact of four MFs subjected to three modes of 3-scale, 5-scale, and 10-scale of fuzzy numbers for predicting the FP of BEs, respectively. As seen, Fig. 4 ( $a$ and b) reflects the effect of four MFs in 3-scale of fuzzy numbers and their statistics test results. The average values of FP under Trimf, Trapmf, Pimf and Gaussmf of MFs in 3-scale of fuzzy numbers were obtained as $0.006,0.006,0.005$ and 0.007 , respectively. Based on the mean comparison test (Tukey's test), there is no significant difference between MFs in 3-scale of fuzzy numbers for estimating FP, statistically (P value $>0.05$ ). In other words, if an interval does contain zero, the corresponding means are not significantly different. Fig. 4 (c and d) shows the effect of four MFs in 5-scale of fuzzy numbers and their statistics test results for estimating the FP. The average values of FP under Trimf, Trapmf, Pimf and Gaussmf MFs in 5-scale of fuzzy numbers were acquired as $0.008,0.008,0.005$ and 0.007 , respectively. As observed, based on Tukey's test, there is no significant difference between MFs in 5-scale of fuzzy numbers for estimating the FP, statistically (Pvalue >0.05). These results are also same for MFs in 10-scale of fuzzy which their outcomes are shown in Fig. 4 (e and f). Therefore, it can be concluded that the impact of four MFs subjected to three modes of 3-scale, 5-scale, and 10-scale of fuzzy numbers was not significant statistically for predicting the FP of BEs.
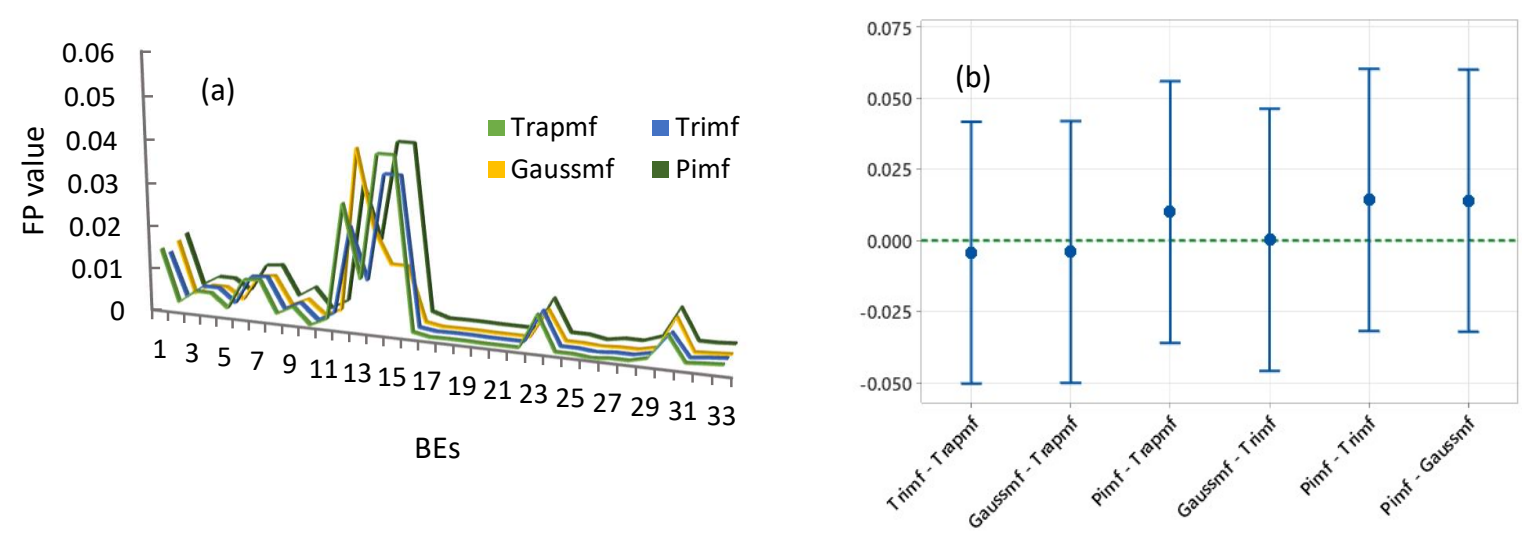

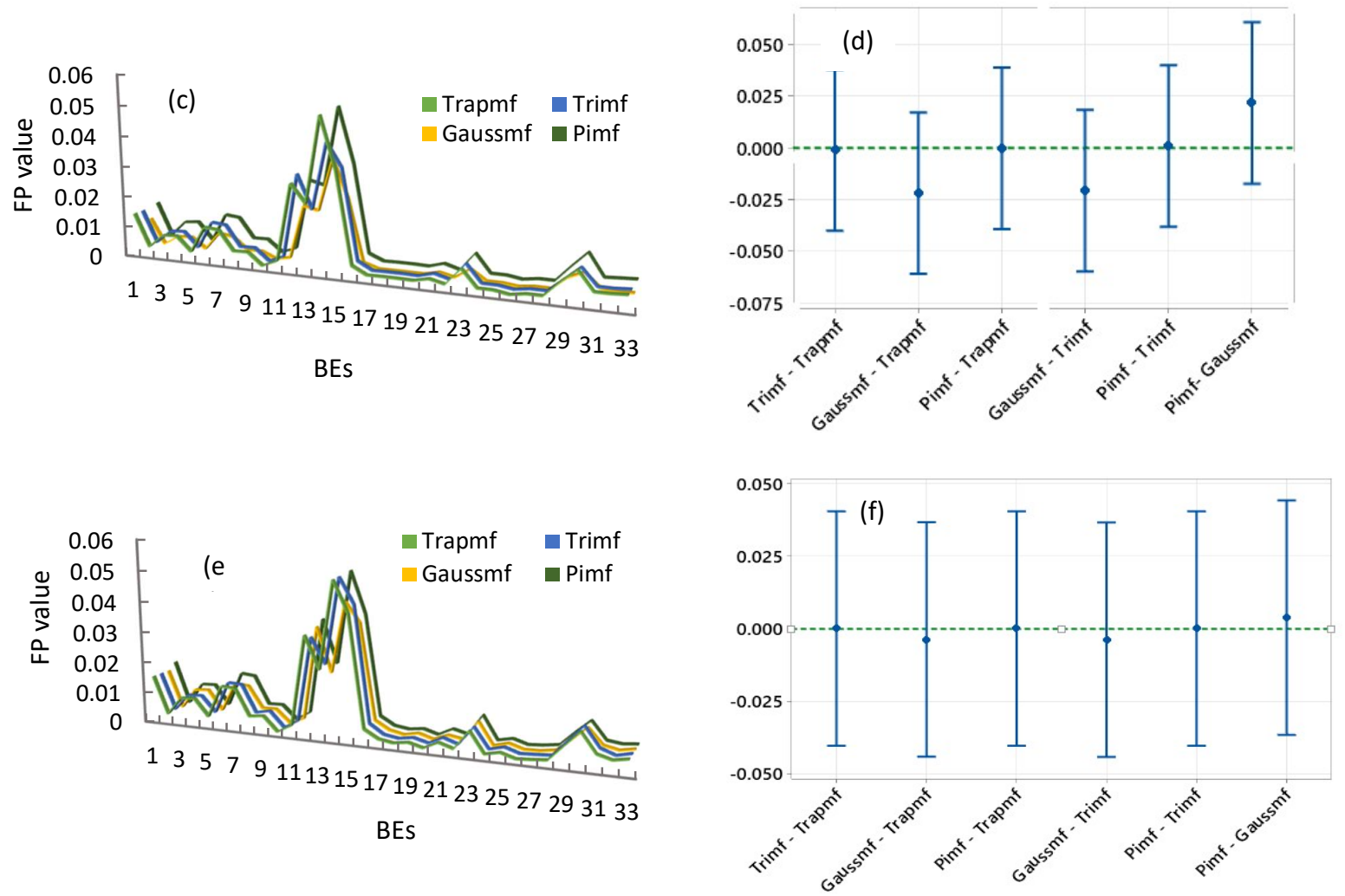

Fig. 4. The results of FP for BEs considering the effects of membership functions.

Fig. 5 ( $a$ and $b$ ) shows the effects of various scales of fuzzy numbers and their statistics test results for estimating FP of BEs. The average values of FP under 3, 5 and 10-scale of fuzzy numbers were gained as 0.006, 0.007 and 0.009, respectively. As seen, based on Tukey's test, there is no significant difference between 3, 5 and 10-scale of fuzzy numbers for predicting FP, statistically (Pvalue $>0.05$ ). In other words, if an interval does contain zero, the corresponding means are not significantly different.
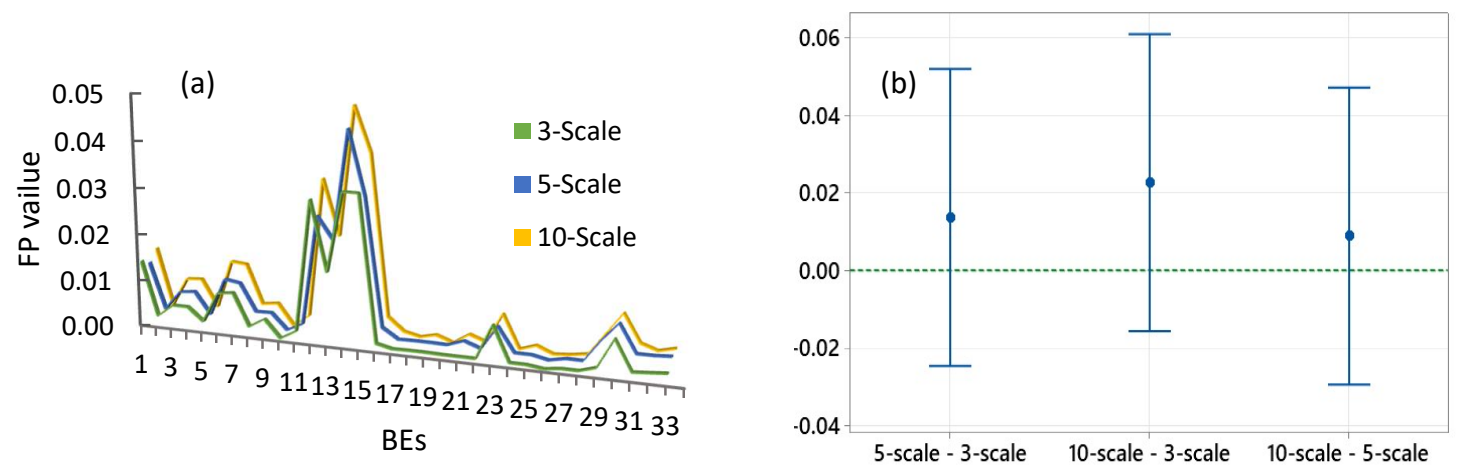

Fig. 5. The results of FP for BEs considering the effects of various scales of fuzzy numbers. 
Additionally, the various defuzzification algorithms were compared to determine the FP of BEs which their results are given in Fig. $6(\mathrm{a}, \mathrm{b})$. The average values of FP under centroid, bisector, mom, lom and som defuzzification algorithms were obtained as 0.008, 0.009, 0.010, 0.008 and 0.102 , respectively. The comparison mean test shows that there is no significant difference between defuzzification algorithms for predicting FP, statistically (P value $>0.05)$. Since in FFTA model, the effect of various attributes such as scales variation and, assorted membership and defuzzification functions was not statistically significant, the average values can be considered to estimate the FP of BEs in the fluid filling system.
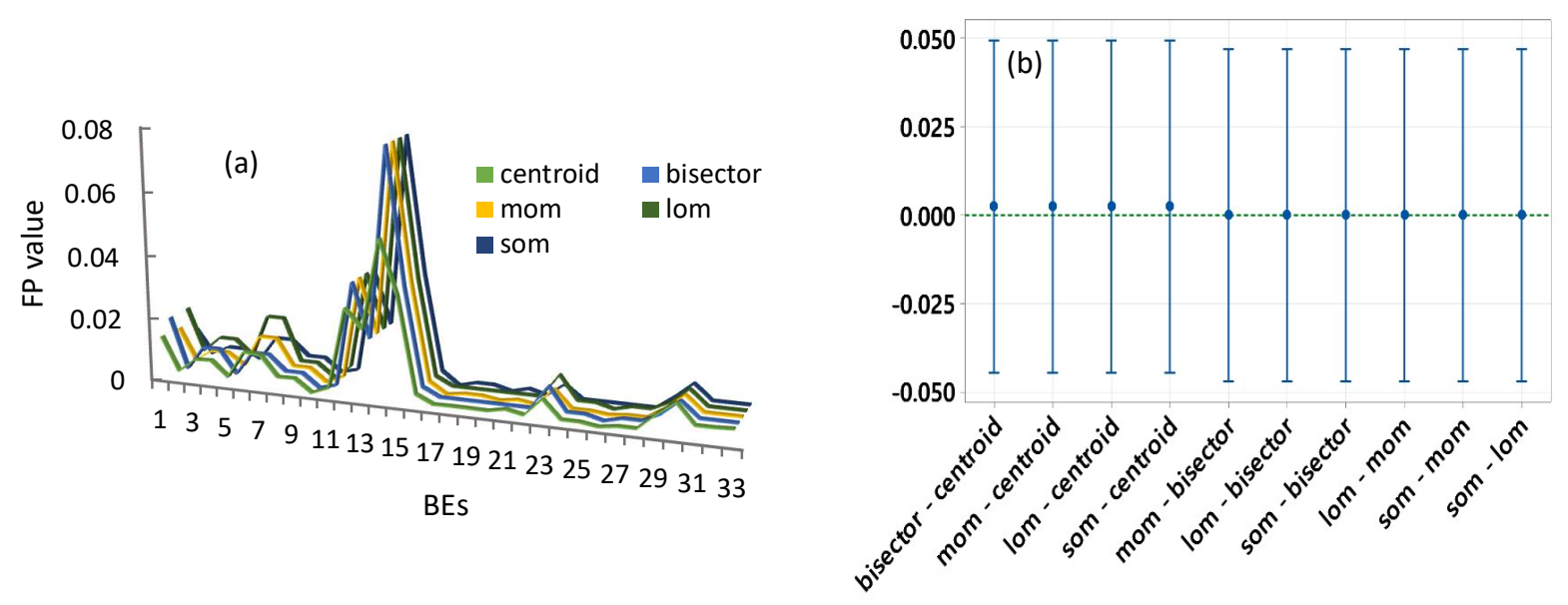

Fig. 6. The results of FP for BEs considering the effects of defuzzification algorithms.

Moreover, due to the static structure assumption of FFTA model throughout estimating FP of BEs, the Bayesian mechanism was employed to consider all possible dynamic interactions between components. The FFTA model is mapped into BN structure shown in Fig. 7. In this BN, G.1 is a leaf node that corresponds to the TE of the FTA model and G.2 to G.16 are the intermediate nodes associated with IEs of the FTA model in which the conditional probability values of each node are occupied based on the type of logic gates ( state $=0$ means faulty, state $=1$ means healthy) using GeNIe 3.0 software (Fig. 8). 


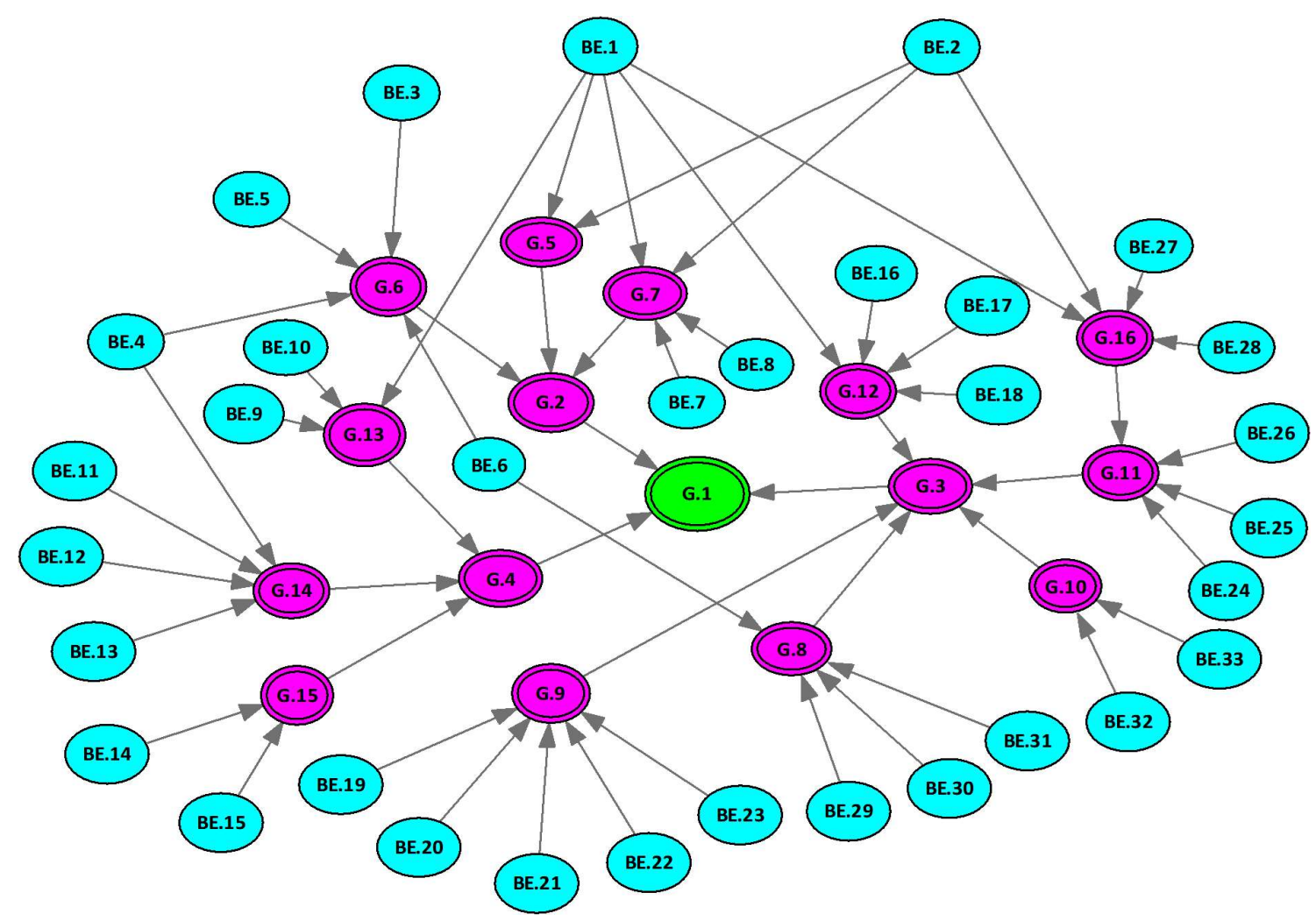

Fig. 7. Bayesian Network of the FFTA model in Fig.3
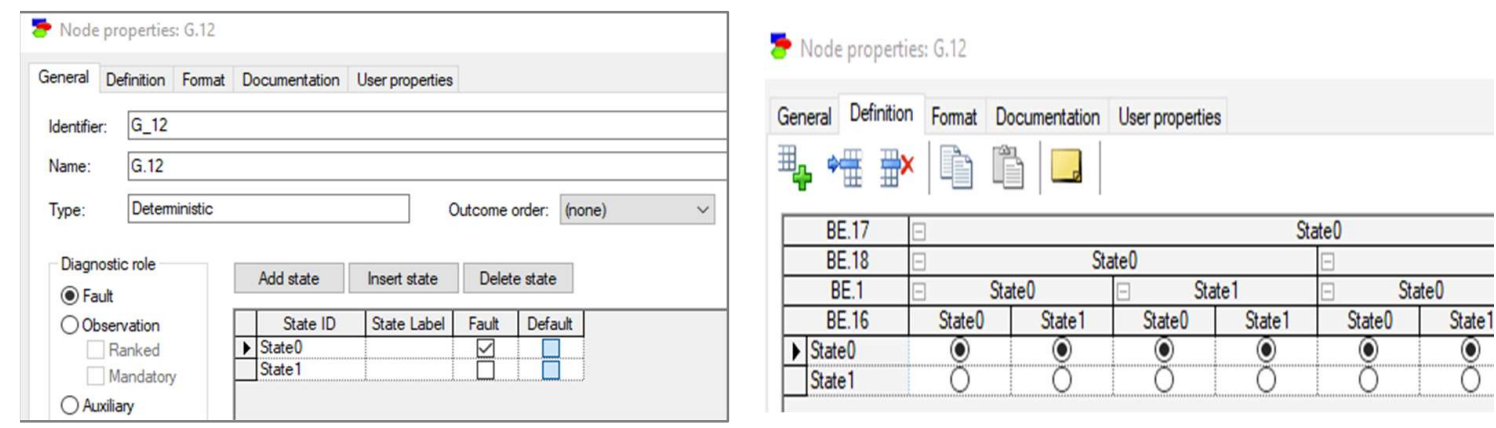

Fig. 8. The conditional probability process of intermediate nodes based on logic gates in GeNIe 3.0 software.

The average values of FP derived from the FFTA method were used as prior probability values of the root nodes in Bayesian mechanism to predict the posterior FP considering all possible dynamic interactions between BEs. Meanwhile, Fig. 9 shows the comparison results of FP based on FFTA and BN models for three sub-units of fluid filling system such as hydraulic-pneumatic circuit, the electronic circuit, and the filling headset along their critical components. As seen, since the $\mathrm{BN}$ method approaches the dynamic relationship between events, the FP values are 
higher in most cases with that of the results of FFTA model. According to the BN analysis, the FP of the leaf node (G.1) or failure of whole filling system was estimated as 0.206 in which the system reliability (exp(-FP)) was around 0.813 . Meanwhile, the FPs of the intermediate nodes including three subsystems such as filling headset (G.2), hydraulic-pneumatic circuit (G.3) and the electronic circuit (G.4) were obtained as $0.057,0.065$ and 0.129 , respectively, in which the reliability (exp (-FP)) was around $0.945,0.936$ and 0.879 , respectively. Among other subintermediate nodes, ABS's failure (G.15), starter's failure (G.14), mini-valve's failure (G.7), pipes' failure (G.8) and Coupling's failure (G.8) have allocated the highest FP values with $0.075,0.058,0.030,0.029$ and 0.027 , respectively. Additionally, the FP of system components such as adapter's failure (BE.14) with $0.042 \mathrm{FP}$ and disruption of cable (BE.15) with 0.034 related to ABS unit, operation error (BE.12) with $0.030 \mathrm{FP}$ and failure of the power button (BE.13) with 0.019 FP related to stater's failure as well as affected by more function fault (BE.1) with 0.014 FP related to O-ring and seal's failure had the highest rank at root nodes level in BN model. As a consequence, it is also worth to perform the convenient maintenance and inspection programs to prevent such failures/faults with the highest FP in fluid filling systems in automotive production lines.
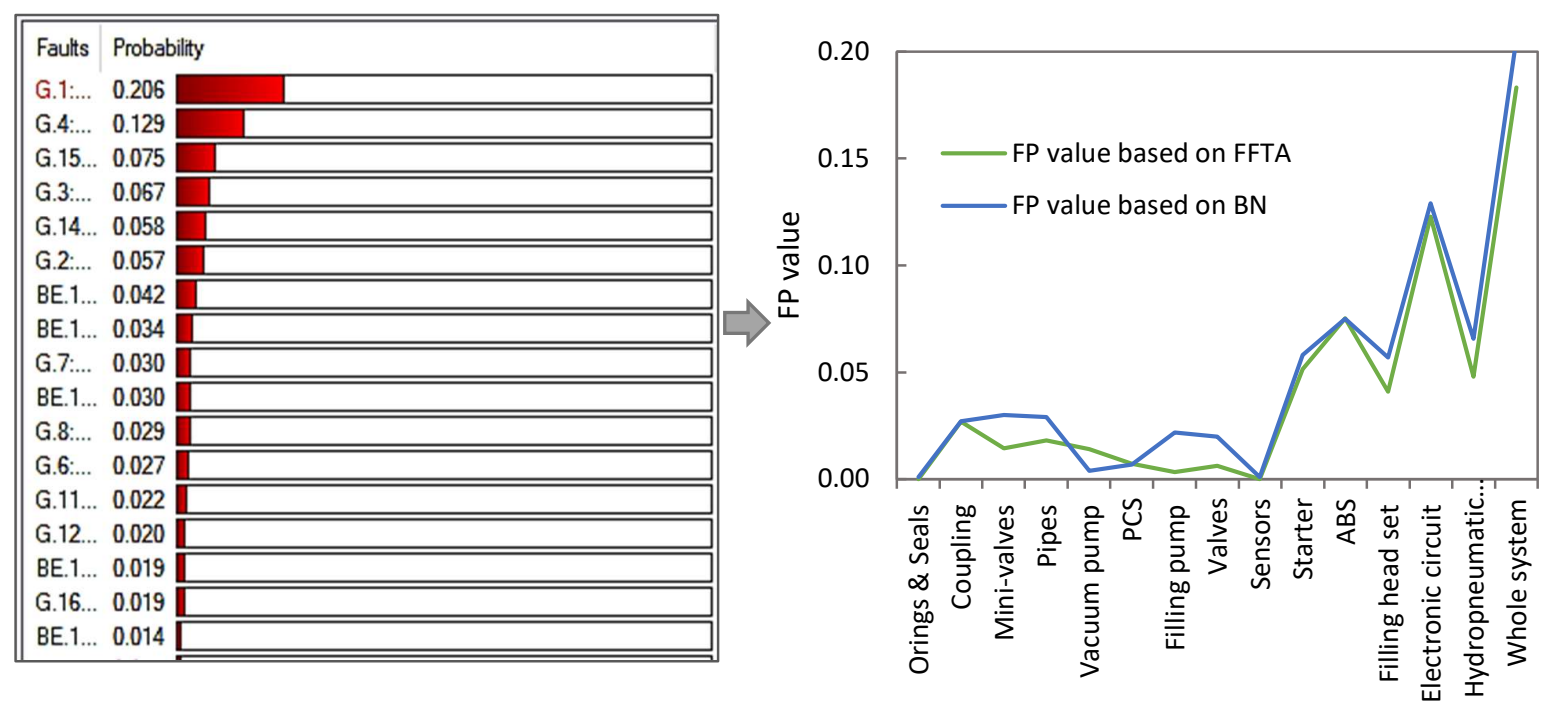

Fig. 9. The comparison results of FP throughout mapping FFTA to BN model 


\subsection{Maintenance optimization results}

A scheduled-maintenance model is proposed subjecting to total expected cost (e.g., repair cost, inspection/preventive cost, and downtime cost) as well as the computed FP or reliability derived from above BN model for a finite period (5000 hours of operation). As shown in Fig.10 (a) for whole fulling filling system, the optimal maintenance intervals considering the repair, inspection, downtime, and total expected costs are estimated as $18^{\text {th }}, 4^{\text {th }}, 10^{\text {th }}$ and, $7^{\text {th }}$, with $1967 \$, 469 \$, 176 \$$, and $3286 \$$ during plan horizon ( $\mathrm{T}=5000$ hours), respectively. Moreover, Fig. 10(b) displays the optimal maintenance intervals for each component of fluid filling system based on total expected cost. the optimal number of intervals for the mini-valves, PCS, valves, sensors, O-rings \& seals, starter, coupling and vacuum pump, were obtained as $10^{\text {th }}, 5^{\text {th }}, 4^{\text {th }}, 5^{\text {th }}$, $3^{\text {rd }}, 6^{\text {th }}$, and $11^{\text {th }}$ with $475 \$, 34 \$, 21 \$, 75 \$, 58 \$, 471 \$$ and $1630 \$$, during plan horizon $(\mathrm{T}=5000$ hours), respectively. The majority of failures affecting on vacuum pump are related to fatigue and strain of spring, as well as filter's failure due to more usage. Corrosion of O-ring and seals due to the chemical impact of fluids results in leakage in couplings and mini-valves within filling headset. The mentioned maintenance activities/intervals would help the engineers to detect and prevent the unexpected failures to achieve the higher safety and availability of complex fluid filling system in automotive production line.
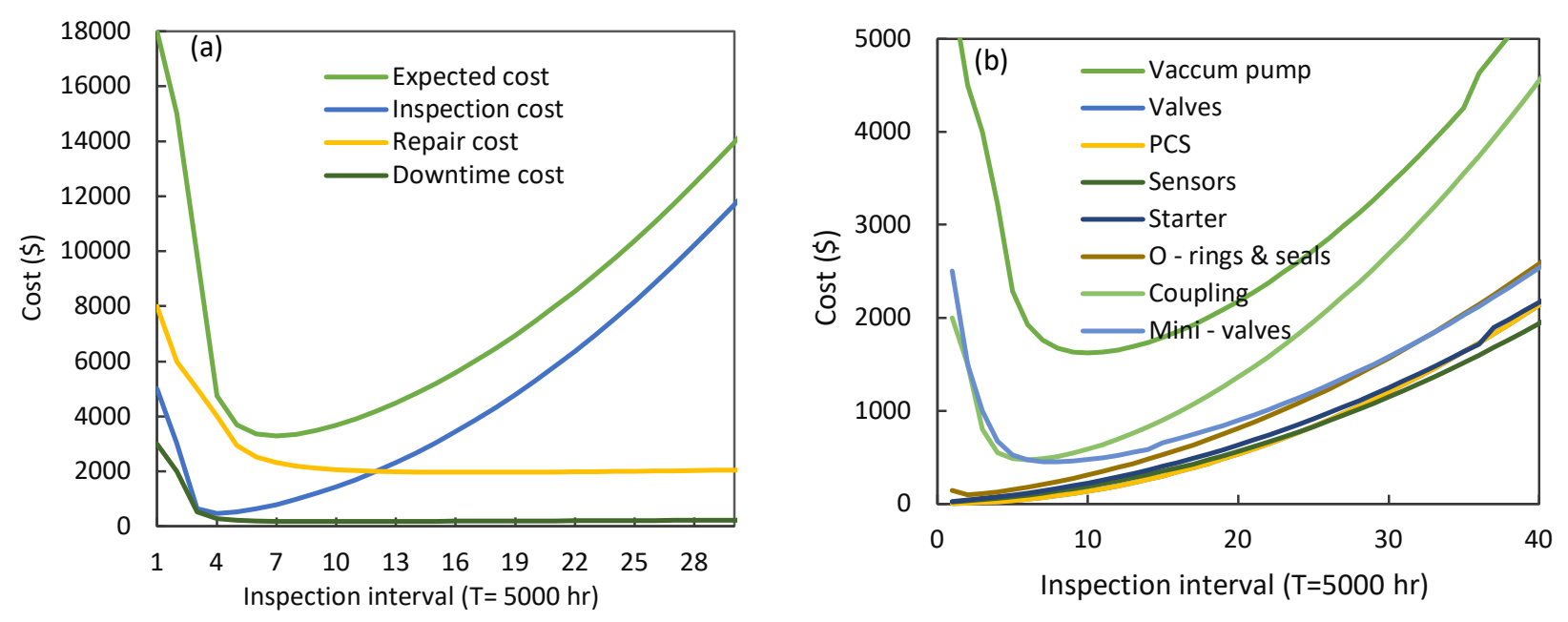

Fig.10. The optimal maintenance intervals for a) whole system and b) critical components 


\section{Conclusion}

This study aimed to propose a knowledge-based framework for optimization of maintenance intervals within manufacturing systems. Knowledge-based approaches are recognized as quite useful alternative with that of data driven-based methods for evaluating risk and reliability, fault detection, and maintenance decision making face the imprecise and insufficient data related to equipment failures, environmental factors, and human activities. We developed a FTA approach to find an optimized scheduled-based maintenance with subjective information derived by domain experts. Since the classical-FTA still suffers from the epistemic uncertainty and static structure limitations, the fuzzy set theory and Bayesian mechanism was conducted to dominate such deals by statistical analyzing the effective attributes such as experts' trait impacts, scales variation and, assorted membership and defuzzification functions. The results revealed that in the fuzzy model, the changes in decision attributes were not statistically significant on FP estimation, while in the Bayesian model considering conditional rules to reflect the interaction between events that had more impact on the FP values. Ultimately, the result of integrated FTTA-BN model was employed in optimization model to find optimal maintenance intervals associated with estimated FP values and total expected cost. To demonstrate the feasibility of the proposed framework, it was implemented in a complex fluid filling system in an automotive production line. As a consequence, the proposed framework could help engineers to make better decisions on how to improve the availability and safety of complex equipment within the automotive manufacturing systems.

\section{Acknowledgment}

The authors gratefully acknowledge the financial support from Ferdowsi University of Mashhad (FUM), Mashhad, Iran which has been a Postdoctoral research project (project no. 46213).

\section{Conflict of interest}

The authors have declared no conflicts of interest for this article. 


\section{References}

1. Aghaei, P., Asadollahfardi, G., \& Katabi, A. (2021). Safety risk assessment in shopping center construction projects using Fuzzy Fault Tree Analysis method. Quality \& Quantity, 1-17.

2.Akhtar, I., \& Kirmani, S. (2020). An Application of Fuzzy Fault Tree Analysis for Reliability Evaluation of Wind Energy System. IETE Journal of Research, 1-14.

3. Alizadeh, S., \& Sriramula, S. (2017). Reliability modelling of redundant safety systems without automatic diagnostics incorporating common cause failures and process demand. ISA Transactions, 71, 599-614.

4.Alzghoul, A., Backe, B., Löfstrand, M., Byström, A., \& Liljedahl, B. (2014). Comparing a knowledge-based and a data-driven method in querying data streams for system fault detection: A hydraulic drive system application. Computers in industry, 65(8), 1126-1135.

5.Aydin, M., Akyuz, E., Turan, O., \& Arslan, O. (2021). Validation of risk analysis for ship collision in narrow waters by using fuzzy Bayesian networks approach. Ocean Engineering, 231, 108973.

6. Ayvaz, S., \& Alpay, K. (2021). Predictive maintenance system for production lines in manufacturing: A machine learning approach using IoT data in real-time. Expert Systems with Applications, 173, 114598 .

7.Badida, P., Balasubramaniam, Y., \& Jayaprakash, J. (2019). Risk evaluation of oil and natural gas pipelines due to natural hazards using fuzzy fault tree analysis. Journal of Natural Gas Science and Engineering, 66, 284-292.

8. Baig, A. A., Ruzli, R., \& Buang, A. B. (2013). Reliability analysis using fault tree analysis: a review. International Journal of Chemical Engineering and Applications, 4(3), 169.

9. Berrouane, M. T., \& Lounis, Z. (2016). Safety assessment of flare system by fault tree analysis. Journal of Chemical Technology and Metallurgy, 51(2), 229-34.

10. Bobbio, A., Portinale, L., Minichino, M., \& Ciancamerla, E. (2001). Improving the analysis of dependable systems by mapping fault trees into Bayesian networks. Reliability Engineering \& System Safety, 71(3), 249-260.

11. Bouejla, A., Chaze, X., Guarnieri, F., \& Napoli, A. (2014). A Bayesian network to manage risks of maritime piracy against offshore oil fields. Safety Science, 68, 222-230.

12. Cheliyan, A. S., \& Bhattacharyya, S. K. (2018). Fuzzy fault tree analysis of oil and gas leakage in subsea production systems. Journal of Ocean Engineering and Science, 3(1), 38-48.

13. Chemweno, P., Pintelon, L., Muchiri, P. N., \& Van Horenbeek, A. (2018). Risk assessment methodologies in maintenance decision making: A review of dependability modelling approaches. Reliability Engineering \& System Safety, 173, 64-77.

14. Chiremsel, Z., Said, R. N., \& Chiremsel, R. (2016). Probabilistic fault diagnosis of safety instrumented systems based on fault tree analysis and Bayesian network. Journal of failure analysis and prevention, 16(5), 747-760. 
15. Farinha, J. M. T. (2018): Asset Maintenance Engineering Methodologies. CRC Press; $1^{\text {st }}$ edition (May 29, 2018). English. Printed in USA. ISBN-10: 1138035890. ISBN-13: 978-1138035898

16. Garmabaki, A. H. S., Marklund, S., Thaduri, A., Hedström, A., \& Kumar, U. (2020). Underground pipelines and railway infrastructure-failure consequences and restrictions. Structure and Infrastructure Engineering, 16(3), 412-430.

17. Gupta, S., Ramkrishna, N., \& Bhattacharya, J. (2006). Replacement and maintenance analysis of longwall shearer using fault tree technique. Mining Technology, 115(2), 49-58.

18. Hänninen, M., Banda, O. A. V., \& Kujala, P. (2014). Bayesian network model of maritime safety management. Expert Systems with Applications, 41(17), 7837-7846.

19. Holgado, M., Macchi, M., \& Evans, S. (2020). Exploring the impacts and contributions of maintenance function for sustainable manufacturing. International Journal of Production Research, 58(23), 7292-7310.

20. Hsu, H. M., \& Chen, C. T. (1996). Aggregation of fuzzy opinions under group decision making. Fuzzy sets and systems, 79(3), 279-285.

21. Huang, H. Z., Zuo, M. J., \& Sun, Z. Q. (2006). Bayesian reliability analysis for fuzzy lifetime data. Fuzzy Sets and Systems, 157(12), 1674-1686.

22. Jin, C., Ran, Y., \& Zhang, G. (2021). Interval-valued q-rung orthopair fuzzy FMEA application to improve risk evaluation process of tool changing manipulator. Applied Soft Computing, 104, 107192.

23. Jong, C. G., \& Leu, S. S. (2013). Bayesian-network-based hydro-power fault diagnosis system development by fault tree transformation. Journal of Marine Science and Technology, 21(4), 367-379.

24. Kabir, S., Geok, T. K., Kumar, M., Yazdi, M., \& Hossain, F. (2019). A method for temporal fault tree analysis using intuitionistic fuzzy set and expert elicitation. IEEE Access, 8, 980-996.

25. Khakzad, N., Khan, F., \& Amyotte, P. (2013). Quantitative risk analysis of offshore drilling operations: A Bayesian approach. Safety science, 57, 108-117.

26. Khan, F. I., \& Haddara, M. (2004). Risk-based maintenance (RBM): A new approach for process plant inspection and maintenance. Process Safety Progress, 23(4), 252-265.

27. Kim, H., Koh, J. S., Kim, Y., \& Theofanous, T. G. (2005). Risk assessment of membrane type LNG storage tanks in Korea-based on fault tree analysis. Korean Journal of Chemical Engineering, 22(1), 18.

28. Kiran, S., Kumar, K. P., Sreejith, B., \& Muralidharan, M. (2016). Reliability evaluation and Risk based maintenance in a process plant. Procedia Technology, 24, 576-583.

29. Kumar, M., \& Kaushik, M. (2020). System failure probability evaluation using fault tree analysis and expert opinions in intuitionistic fuzzy environment. Journal of Loss Prevention in the Process Industries, 67, 104236.

30. Kumar, M., \& Yadav, S. P. (2012). The weakest t-norm based intuitionistic fuzzy fault-tree analysis to evaluate system reliability. ISA transactions, 51(4), 531-538. 
31. Kumar, S. (2014). A knowledge-based reliability engineering approach to manage product safety and recalls. Expert Systems with Applications, 41(11), 5323-5339.

32. Kuzu, A. C., Akyuz, E., \& Arslan, O. (2019). Application of fuzzy fault tree analysis (FFTA) to maritime industry: a risk analysing of ship mooring operation. Ocean Engineering, 179, 128-134.

33. Lambert, H. E. (2004). Use of fault tree analysis for automotive reliability and safety analysis. SAE transactions, 690-696.

34. Lapp, S. A. (2005). Applications of fault tree analysis to maintenance interval extension and vulnerability assessment. Process safety progress, 24(2), 91-97.

35. Leimeister, M., \& Kolios, A. (2018). A review of reliability-based methods for risk analysis and their application in the offshore wind industry. Renewable and Sustainable Energy Reviews, 91, 10651076.

36. Liu, Yan, Yue Wu, and Zbigniew Kalbarczyk. "Smart maintenance via dynamic fault tree analysis: A case study on Singapore MRT system." In 2017 47th Annual IEEE/IFIP International Conference on Dependable Systems and Networks (DSN), pp. 511-518. IEEE, 2017.

37. Onisawa, T. (1988). An approach to human reliability in man-machine systems using error possibility. Fuzzy sets and Systems, 27(2), 87-103.

38. Purba, J. H., Lu, J., Zhang, G., \& Ruan, D. (2011). Failure possibilities for nuclear safety assessment by fault tree analysis. International Journal of Nuclear Knowledge Management, 5(2), 162-177.

39. Rajakarunakaran, S., Kumar, A. M., \& Prabhu, V. A. (2015). Applications of fuzzy faulty tree analysis and expert elicitation for evaluation of risks in LPG refueling station. Journal of Loss Prevention in the Process Industries, 33, 109-123.

40. Rausand, M. (2013). Risk assessment: theory, methods, and applications (Vol. 115). John Wiley \& Sons.

41. Rezaei, E. (2017). A new model for the optimization of periodic inspection intervals with failure interaction: A case study for a turbine rotor. Case studies in engineering failure analysis, 9, 148-156.

42. Rice, W. P. (2007). Medical device risk-based evaluation and maintenance using fault tree analysis. Biomedical instrumentation \& technology, 41(1), 76-82.

43. Rusin, A., \& Wojaczek, A. (2012). Application of fault tree analysis in the maintenance intervals planning for power unit systems. Archiwum Energetyki, 42.

44. Smith, D., Veitch, B., Khan, F., \& Taylor, R. (2017). Understanding industrial safety: Comparing Fault tree, Bayesian network, and FRAM approaches. Journal of Loss Prevention in the Process Industries, 45, 88-101.

45. Soltanali, H., Garmabaki, A. H. S., Thaduri, A., Parida, A., Kumar, U., \& Rohani, A. (2019). Sustainable production process: An application of reliability, availability, and maintainability methodologies in automotive manufacturing. Proceedings of the Institution of Mechanical Engineers, Part O: Journal of Risk and Reliability, 233(4), 682-697. 
46. Soltanali, H., Rohani, A., Abbaspour-Fard, M. H., \& Farinha, J. T. (2021). A comparative study of statistical and soft computing techniques for reliability prediction of automotive manufacturing. Applied Soft Computing, 98, 106738.

47. Soltanali, H., Rohani, A., Tabasizadeh, M., Abbaspour-Fard, M. H., \& Parida, A. (2020a). An improved fuzzy inference system-based risk analysis approach with application to automotive production line. Neural Computing and Applications, 32(14), 10573-10591.

48. Soltanali, H., Rohani, A., Tabasizadeh, M., Abbaspour-Fard, M. H., \& Parida, A. (2020b). Operational reliability evaluation-based maintenance planning for automotive production line. Quality Technology \& Quantitative Management, 17(2), 186-202.

49. Summers, A. E. (2000). Viewpoint on ISA TR84. 0.02 — simplified methods and fault tree analysis. 50. Tong, X., Fang, W., Yuan, S., Ma, J., \& Bai, Y. (2018). Application of Bayesian approach to the assessment of mine gas explosion. Journal of Loss Prevention in the Process Industries, 54, 238-245.

51. Venkatasubramanian, V., Rengaswamy, R., Yin, K., \& Kavuri, S. N. (2003). A review of process fault detection and diagnosis: Part I: Quantitative model-based methods. Computers \& chemical engineering, 27(3), 293-311.

52. Volkanovski, A., Čepin, M., \& Mavko, B. (2009). Application of the fault tree analysis for assessment of power system reliability. Reliability Engineering \& System Safety, 94(6), 1116-1127.

53. Yazdi, M. (2017). Hybrid probabilistic risk assessment using fuzzy FTA and fuzzy AHP in a process industry. Journal of Failure Analysis and Prevention, 17(4), 756-764.

54. Yazdi, M., \& Darvishmotevali, M. (2018, August). Fuzzy-based failure diagnostic analysis in a chemical process industry. In International Conference on Theory and Applications of Fuzzy Systems and Soft Computing (pp. 724-731). Springer, Cham.

55. Yazdi, M., \& Kabir, S. (2017). A fuzzy Bayesian network approach for risk analysis in process industries. Process Safety and Environmental Protection, 111, 507-519.

56. Yazdi, M., \& Soltanali, H. (2019). Knowledge acquisition development in failure diagnosis analysis as an interactive approach. International Journal on Interactive Design and Manufacturing (IJIDeM), 13(1), 193-210.

57. Yazdi, M., \& Zarei, E. (2018). Uncertainty handling in the safety risk analysis: an integrated approach based on fuzzy fault tree analysis. Journal of failure analysis and prevention, 18(2), 392-404. 58. Yazdi, M., Kabir, S., \& Walker, M. (2019). Uncertainty handling in fault tree-based risk assessment: State of the art and future perspectives. Process Safety and Environmental Protection, 131, 89-104.

59. Yazdi, M., Korhan, O., \& Daneshvar, S. (2020). Application of fuzzy fault tree analysis based on modified fuzzy AHP and fuzzy TOPSIS for fire and explosion in the process industry. International journal of occupational safety and ergonomics, 26(2), 319-335. 
60. Yazdi, M., Nikfar, F., \& Nasrabadi, M. (2017). Failure probability analysis by employing fuzzy fault tree analysis. International Journal of System Assurance Engineering and Management, 8(2), 1177-1193.

61. Yildiz, A. E., Dikmen, I., Birgonul, M. T., Ercoskun, K., \& Alten, S. (2014). A knowledge-based risk mapping tool for cost estimation of international construction projects. Automation in Construction, 43, 144-155.

62. Yuhua, D., \& Datao, Y. (2005). Estimation of failure probability of oil and gas transmission pipelines by fuzzy fault tree analysis. Journal of loss prevention in the process industries, 18(2), 83-88. 63. Zhang, G., Thai, V. V., Yuen, K. F., Loh, H. S., \& Zhou, Q. (2018). Addressing the epistemic uncertainty in maritime accidents modelling using Bayesian network with interval probabilities. Safety science, 102, 211-225.

64. Zheng, Y., Zhao, F., \& Wang, Z. (2019). Fault diagnosis system of bridge crane equipment based on fault tree and Bayesian network. The International Journal of Advanced Manufacturing Technology, 105(9), 3605-3618.

65. Zhou, H., \& Ren, H. (2020). A novel ranking function-based triangular intuitionistic fuzzy fault tree analysis method. Journal of Intelligent \& Fuzzy Systems, (Preprint), 1-9. 